\title{
Comparison of the effects of platelet-rich or growth factor-rich plasma on intestinal anastomosis healing in pigs
}

Gessica Giusto, Cristina Vercelli, Selina lussich, Massimiliano Tursi, Giovanni Perona and Marco Gandini* (D)

\begin{abstract}
Background: The use of autologous platelet-rich plasma (PRP) and plasma rich in growth factors (PRGF) has been proposed for the treatment of several acute and chronic syndromes, such as corneal epithelial defects and dry eye syndrome, gum bleeding during oral surgery, and in orthopaedic surgery. We hypothesized that PRGF, rather than PRP, could be more effective because of its intrinsic characteristics in promoting the healing of intestinal anastomosis. The purpose of the present study was to evaluate and compare the effects of PRP and PRGF on various parameters of anastomotic healing in a swine model.

Methods: Eight female pigs were randomly assigned to two groups and subjected to hand sewn jeujuno-jejunal appositional extramucosal anastomoses. For each animal, a total of six anastomoses were performed: two were considered controls and received no treatment, while the remaining four anastomoses were treated with PRP or PRGF of which both were prepared at a platelet concentration that was respectively 3.4-fold and 2.81-fold higher than the original platelet count. In each animal, either PRP or PRGF was used as a treatment, to avoid interference among products. Animals were euthanized after 8 days and the anastomoses were evaluated and compared for the presence of adhesions, anastomotic leakage, bursting pressure, and histological appearance.
\end{abstract}

Results: The concentration of platelets in PRP was 3.41-fold higher (range, 3.20-4.24) that the concentration in whole blood, while the concentration in PRGF was 2.81-fold higher (range, 2.89-4.88).

The results obtained from the present study highlighted that there are no differences between anastomotic samples treated with either PRP or PRGF preparations, except for a significant increase in epithelization of the intestinal mucosa at the anastomotic site in the PRGF group.

Conclusions: Both PRP and PRGF suspensions should be considered a safe strategy and represent a relatively lowcost technology that is flexible enough to be applied in several therapeutic fields. No true benefit could be proven in our study compared to the no treatment following anastomoses formation, with the exception of enhanced epithelization of the mucosa in the PRGF group.

Keywords: Platelet rich plasma, Anastomosis, Leakage, Pig

\footnotetext{
* Correspondence: marco.gandini@unito.it

Department of Veterinary Sciences, University of Turin, Largo Paolo Braccini,

n. 2, Grugliasco, 10095 Turin, Italy
}

(c) The Author(s). 2017 Open Access This article is distributed under the terms of the Creative Commons Attribution 4.0 International License (http://creativecommons.org/licenses/by/4.0/), which permits unrestricted use, distribution, and reproduction in any medium, provided you give appropriate credit to the original author(s) and the source, provide a link to the Creative Commons license, and indicate if changes were made. The Creative Commons Public Domain Dedication waiver (http://creativecommons.org/publicdomain/zero/1.0/) applies to the data made available in this article, unless otherwise stated. 


\section{Background}

Surgical techniques are continuously evolving to be more efficient for patients and to reduce the duration of postoperative recovery. In gastrointestinal surgery, a major challenge is represented by anastomosis dehiscence [1]. Recently, several studies have focused on identifying a strategy to reduce this complication, which represents a failure in the surgical procedure that can be potentially fatal [2]. Some of these investigations have suggested using substances that are able to accelerate the wound healing process. Regenerative medicine may offer some important guidance in this area [3]. The use of platelet-rich plasma (PRP) alone or in combination with growth factors (preparations rich in growth factors, PRGF) [4] naturally secreted by platelets, such as platelet-derived growth factor (PDGF), transforming growth factor- $\beta$ (TGF- $\beta$ ), and vascular endothelial growth factor (VEGF), may play a role in improving anastomotic healing [3]. PRP and PRGF differ in composition and methods of preparation. Several methods to produce a biologically active product have been developed and they differ in the concentration of growth factors, white blood cells, and characteristics of the fibrin scaffold $[5,6]$. PRP was defined by Ehrenfest et al. [7] as a preparation with leucocytes and with a lowdensity fibrin network after activation. PRGF contains moderate platelet concentration, no leukocytes, nor a three dimensional fibrin scaffold $[5,6]$. From a therapeutic perspective, there are two main advantages in using PRGF. First is the release of proteins and growth factors from platelets that stimulate regeneration. Second is the creation of a three-dimensional fibrin matrix that retains and releases growth factors and acts as a temporal scaffold for the cells [8]. Furthermore, the absence of leukocytes is an important characteristic of PRGF. Leukocytes produce metalloproteinase, free radicals, reactive oxygen species, and nitrogen, which can cause damge to healing tissues [8]. The rationale for PRP therapy lies in reversing the blood ratio by reducing the amount of red blood cells, which are less useful in the healing process, to approximately $5 \%$ and to increase the amount of platelets to $94 \%$ to stimulate recovery [5]. The use of autologous PRP and PRGF has been proposed for the treatment of several acute and chronic syndromes, such as for corneal epithelial defects and dry eye syndrome, avoiding gum bleeding during oral surgery, and in orthopaedic surgery [4, 9-12]. The most important feature of PRP is that autologous products circumvent immunogenic reactions and disease transmission. According to Dr. Anitua, who first proposed the technique, PRGF has some peculiar characteristics that may favour its use over that of PRP. In particular, the lower number of leucocytes in the PRGF may improve healing because of the absence of inflammatory cells [13].

With each passing year, the number of relevant articles published in PubMed has increased (accessed October 13, 2015); however it is difficult to compare all published results, given the lack of uniformity in processing platelets and the different techniques used. Papers dealing with the possible use of PRP have not been in complete agreement. The majority suggest that these substances have a positive effect on wound healing of colonic anastomosis, while one paper [3] indicated that application of PRP could only increase fibrosis and granulation tissue, without improving the breaking strength of anastomotic sites. To date, all studies have dealt with PRP, while none have tested the use of PRGF on anastomosis healing.

Our hypothesis was that PRGF, rather than PRP, could be more effective in promoting the healing of intestinal anastomosis because of its intrinsic characteristics (i.e., low number of leukocytes). The purpose of the present study was to evaluate and compare the effects of PRP and PRGF on various parameters of anastomotic healing in a swine model.

\section{Results}

\section{Assessment of the characteristics of autologous preparations}

Results from assessing the characteristics of the autologous preparations are reported in Table 1 . The concentration of platelets and leukocytes of freshly collected whole blood for both groups were within the normal range of values for Landrace pigs (platelets $217-770 \times 10^{3} / \mathrm{mL}$, leukocytes $7-20 \times 10^{3} / \mathrm{mL}$ ) (http://www.ahc.umn.edu/rar/ refvalues.html, accessed 15-06-2017). The concentration of platelets in PRP was 3.41-fold higher (range, 3.20-4.24)

Table 1 Comparison of the characteristics of the preparations (median-range)

\begin{tabular}{|c|c|c|c|c|c|c|}
\hline & \multicolumn{3}{|l|}{ Group PRP } & \multicolumn{3}{|l|}{ Group PRGF } \\
\hline & $\begin{array}{l}\text { Whole blood } \\
\left.\text { (cells } \times 10^{3} / \mu \mathrm{L}\right)\end{array}$ & $\begin{array}{l}\text { PRP } \\
\text { (cells } \times 10^{3} / \mu \mathrm{L} \text { ) }\end{array}$ & Prep/WB ratio & $\begin{array}{l}\text { Whole blood } \\
\left(\text { cells } \times 10^{3} / \mu \mathrm{L}\right)\end{array}$ & $\begin{array}{l}\text { PRGF } \\
\left.\text { (cells } \times 10^{3} / \mu \mathrm{L}\right)\end{array}$ & Prep/WB ratio \\
\hline Platelet count & $\begin{array}{l}387 \\
(295-622)\end{array}$ & $\begin{array}{l}1321 \\
(945-2641)\end{array}$ & $\begin{array}{l}3.4 \\
(2.5-4.9)\end{array}$ & $\begin{array}{l}376 \\
(285-495)\end{array}$ & $\begin{array}{l}1565 \\
(825-2420)\end{array}$ & $\begin{array}{l}3.4 \\
(1.5-5.3)\end{array}$ \\
\hline Leukocyte Count & $\begin{array}{l}13.76 \\
(11.5-17)\end{array}$ & $\begin{array}{l}1.72^{a} \\
(0.8-3.5)\end{array}$ & $\begin{array}{l}0.132^{b} \\
(0.05-0.20)\end{array}$ & $\begin{array}{l}13.85 \\
(10.2-16)\end{array}$ & $\begin{array}{l}0.17^{a} \\
(0.01-1.020)\end{array}$ & $\begin{array}{l}0.02^{\mathrm{b}} \\
(0.001-0.67)\end{array}$ \\
\hline
\end{tabular}

a $P=0.0007$

${ }^{\mathrm{b}} P=0.0002$ 
than the concentration of whole blood, while in PRGF, it was 2.81-fold higher (range, 2.89-4.88).

\section{Surgical procedures}

All animals recovered uneventfully from anaesthesia and there were no surgery-related complications in the postoperative period

\section{Macroscopic examination}

Macroscopic evaluation showed no evidence of leaking in any anastomoses in either the control or treated animals. Anastomoses treated with PRP showed more adhesion formation (10/16) compared to those treated with PRGF $(5 / 16)$ or controls (6/16); nevertheless, this increase in adhesion formation was not significantly different $(P=0.169)$. When adhesion formation was noted, it was scored 1 or 2, with only one case in the PRP group that was scored 3 (Fig. 1). The median adhesion score for group PRP was $1(0-3)$ and 0 for group PRGF (0-2).

\section{Bursting pressure}

Bowel sections treated with PRGF demonstrated more resistance at the bursting pressure test (Table 2), although not significantly different from controls and PRP-treated anastomoses. PRP-treated anastomoses were significantly less resistant than intact intestinal tissue.

\section{Histology}

Results of the histological evaluation are reported in Table 3. There was no significant difference among the samples treated with PRP, PRGF, and controls relative to inflammatory infiltrate, proliferation of fibroblasts, neovascularisation, or deposition of collagen (Fig. 2).

Microscopic evaluation highlighted a significant increase in epithelization of the mucosa in the PRGF-treated group (Table 3)

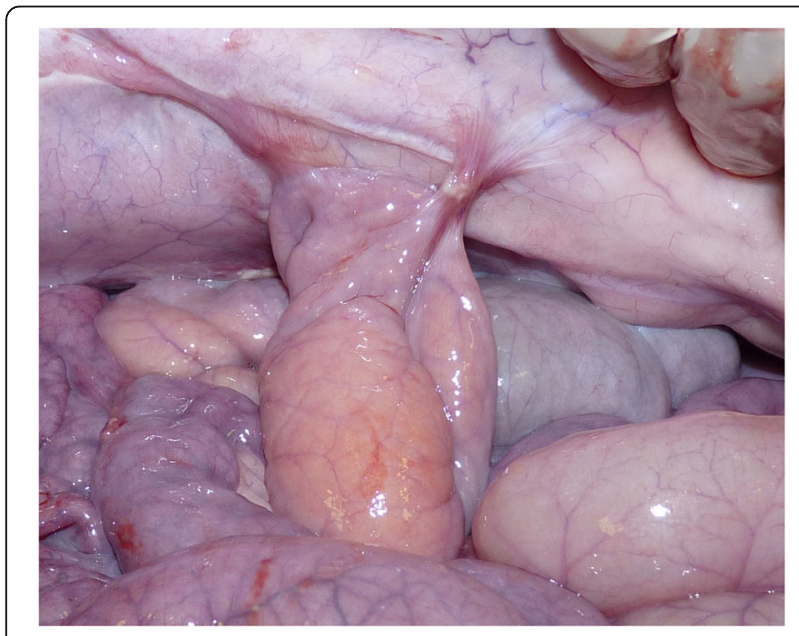

Fig. 1 A grade 3 adhesion in the PRP group
Table 2 Bursting pressure measurements (median-range)

\begin{tabular}{lllll}
\hline & $\begin{array}{l}\text { PRP-treated } \\
\text { anastomoses }\end{array}$ & $\begin{array}{l}\text { PRGF-treated } \\
\text { anastomoses }\end{array}$ & $\begin{array}{l}\text { Control } \\
\text { anastomoses }\end{array}$ & $\begin{array}{l}\text { Intact } \\
\text { bowel }\end{array}$ \\
\hline Bursting & 117.5 & 165 & 154.0 & 175 \\
pressure & $(80-190)^{\mathrm{a}}$ & $(100-190)$ & $(50-180)$ & $(160-190)^{\mathrm{a}}$ \\
\hline
\end{tabular}

${ }^{\mathrm{a}} P=0.0007$

\section{Discussion}

During the early stages of intestinal wound healing, platelets play an important role during the initial $72 \mathrm{~h}$ after injury [14]. The release of growth factors from platelets mediates the healing process [15]. The use of autologous substances, such as platelet rich products, has been considered a promising advance for new surgical and clinical approaches. Furthermore, recent advances in their use should eliminate the risk of immunological reactions. Moreover, it is assumed that they increase the local growth factor concentrations at the site of healing, thereby accelerating the wound healing process [15]. This type of biological treatment mimics natural tissue healing, while optimising and reducing the time required [5]. Thus, all proteins necessary for tissue repair are released locally.

To the best of our knowledge, this is the first study comparing PRP and PRGF healing effects on intestinal anastomosis.

Bursting pressure is considered to be a more accurate measure as it reflects the physiologic strain in intestinal tissue rather than than the breaking strength [15]. Intestinal healing is characterised by three phases of healing: inflammatory, proliferative, and the maturation phases. These steps occur between post-operative days 0 and 4, from days 3 to 14 , and from days 10 to 180 , respectively [15]. Usually, during the first phase, fibrin contributes to wound healing and strength, but the major strain is allocated to the sutures. In a normal setting, between days 3 and 4 , the anastomotic strength is lower due to fibrinolysis and collagen deposition. Under such conditions, dehiscence of the suture line can easily occur. This study considered only the proliferative phase because all pigs were euthanized at day 8 after surgery. We specifically took into consideration this period because, in this phase, macrophages are involved in fibrin debridement (occurring in the inflammatory phase) and natural growth factor production is at its maximum peak and might modulate fibrosis and angiogenesis [16].

Table 3 Results of the histological evaluation (median-range)

\begin{tabular}{lllll}
\hline & PRGF & PRP & Control & $p$ value \\
\hline Epithelization & $2.5(0-3)^{\mathrm{a}, \mathrm{b}}$ & $1(0-2)^{\mathrm{a}}$ & $0.5(0-2)^{\mathrm{b}}$ & $\begin{array}{l}\mathrm{a}=0.0012 \\
\mathrm{~b}=0.0005\end{array}$ \\
Inflammation & $3(1-3)$ & $2.5(2-3)$ & $3(1-3)$ & 0.668 \\
Fibrosis & $2(1-3)$ & $3(1-3)$ & $3(1-3)$ & 0.135 \\
Neovascularization & $1(0-2)$ & $2(1-3)$ & $2(1-3)$ & 0.079 \\
Collagen & $2.5(1-3)$ & $2(1-3)$ & $2(1-3)$ & 0.971 \\
\hline
\end{tabular}




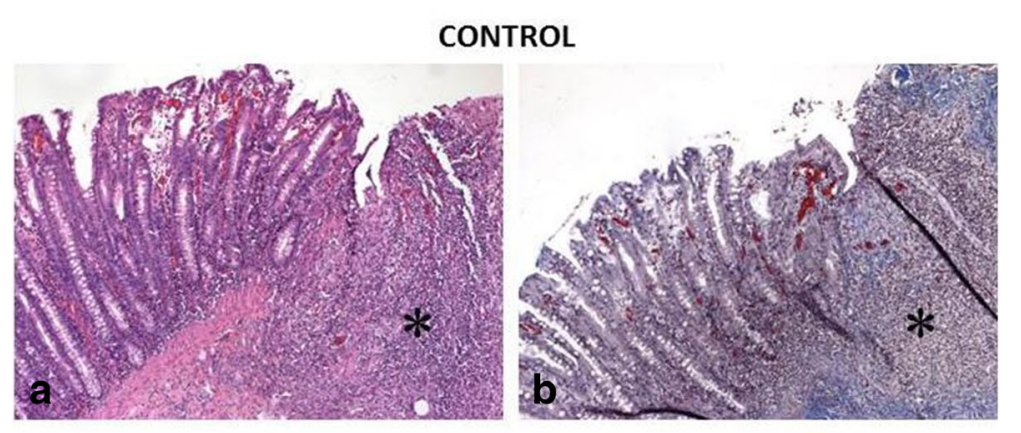

PRGF

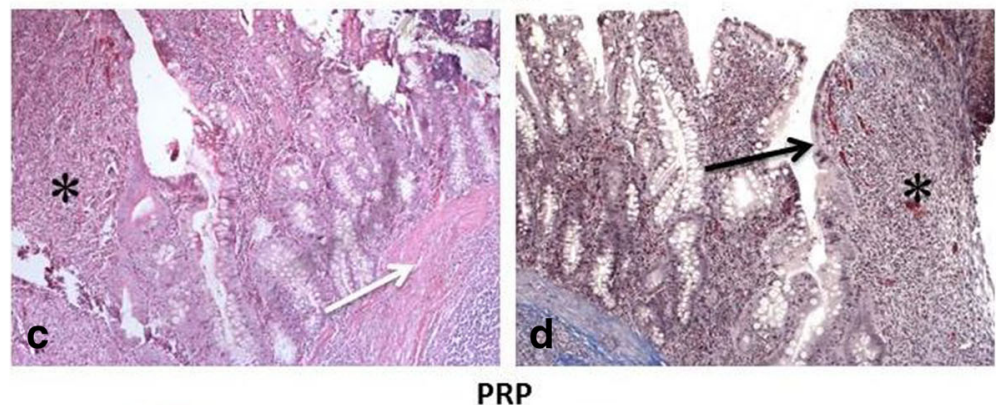

PRP

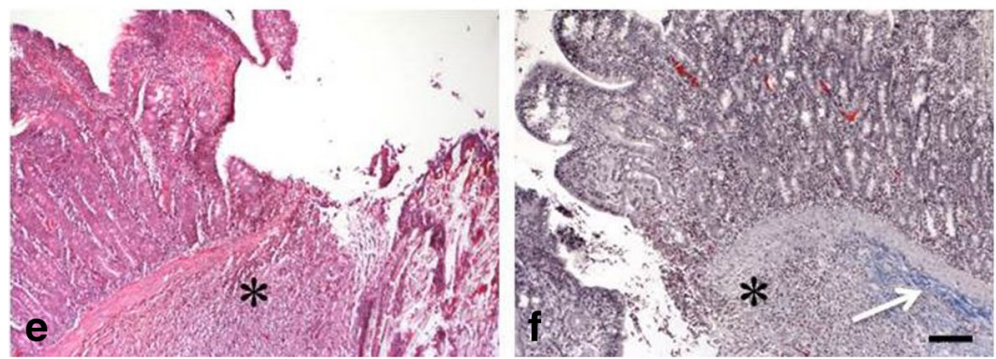

Fig. 2 Histological appearance of the anastomotic site in each group: a,b CONTROL. c,d PRGF. e,f PRP, Bar: $100 \mu$, a, c, e Hematoxylin and eosin 10x. b, d, f trichrome Masson staining 10x, *Inflammation, Black Arrow: epithelization, White arrow: fibrosis

The application of a PRP or a PRGF treatment should promote intestinal healing and lower the risk of dehiscence.

The results obtained from the present study highlighted that there are no significant differences between anastomotic samples treated with either PRP or PRGF preparations. Bursting pressure showed a high resistance of PRGFtreated anastomoses, in comparison with PRP treated ones. A statistical significance was found between the PRPtreated anastomoses and the healthy intestine. This finding could be due to the presence of leukocytes in the PRP, which release substances (such as metalloproteinases) that may damage healing tissues. Leukocytes, by participating in an inflammatory cascade, could decrease anastomotic bursting pressure more so than in the control anastomoses, where leukocytes concentration is lower. During the proliferative phase, an increase in neo-vascularisation, fibroblast proliferation, and collagen deposition should be noted along with a decrease in inflammation. However, in our study, no difference was found between groups regarding these parameters. Our results showed only a better epithelization of the jejunal mucosa in the PRGF-treated group. The data from this study are partially in accordance with the results of Fresno et al. [3]. The authors employed a similar experimental design, but, following treatment of the anastomosis with the PRP suspension, the anastomotic sites were covered with omentum. This could cause an increase in fibrosis at the anastomotic sites that could be considered a bias. In the present study, in order to avoid this type of interference, the omentum was not placed on the anastomosis site.

In our study anastomoses treated with PRP showed more adhesion formation compared to samples treated with PRGF or controls. These results could be explained by the composition of the PRP, which contains leukocytes and platelets. Adhesion formation is triggered by inflammatory mediators and by dispersion of fibrin onto the affected surface [17]. Converseley, as reported by Anitua et al. [6], who first proposed the technique, PRGF was found to not contain any leukocytes. Instead, PRGF was found to contain a moderate platelet concentration, 
which would circumvent all potential pro-inflammatory effects that could explain the higher number of adhesions in the PRP group.

As already argued by Fresno et al. [3], the immersion of the intestinal edges in the treatment bath may present some issues. Intestinal edges after a resection usually bleed, and may be contaminated with intestinal contents, thus potentially influencing PRP or PRGF efficiency and concentration.

Some authors [18, 19] have investigated platelet rich plasma and considered eliminating leukocytes from such preparation so as to avoid higher concentrations of proinflammatory cytokines that might reduce tissue healing. The study by Anitua et al. [12] used PRP that was either rich or poor in leucocytes in order to evaluate whether this could influence tissue healing; however, it appeared that leucocyte concentrations did not interfere with wound healing after oral surgery. Some issues were raised by Del Buono and colleagues [20] against the indiscriminate use of PRP or PRGF. They explained that these substances could successfully improve wound healing in orthopaedic and oral surgery, but should be carefully handled for other applications, because concentrations of PRP or PRGF, doses, timing and length of applications have not been defined yet. Yamaguchi et al. [15] investigated different concentrations of PRP to evaluate dose-specific effects on intestinal anastomosis in rats and established that the optimal concentration of platelets should be around 2.5-fold higher than that found in the initial blood collection. As also reported by Yamaguchi et al. [15], clinicians should be cautious in thinking "if some is good, more is better" as it does not apply to PRP applications. It has been shown that platelet concentrations of 4.5-5.5fold higher than that found in whole blood may interfere with the normal wound healing process [14, 21]. In our study, platelet concentrations achieved in both groups (PRGF and PRP) were 3.4- and 3.5-fold higher, respectively, than the initial ratio. This is higher than what is considered the optimal ratio to achieve a maximum effect from plasma-rich preparations on intestinal anastomosis [15] and perhaps this could be the cause of the poor effect demonstrated in our study. Reducing the platelet concentration to around 2.5-times the plasma concentration or changing the method of its application at the anastomotic site may yeld different results.

Fresno and colleagues [3] did not find a significant difference in breaking strength when PRP was applied to anastomoses in pigs, but they found a higher degree of fibrosis and granulation tissue. While the finding on bursting pressure is in accordance with our study, the difference between their histological findings and ours may be due to a certain degree of subjectiveness in the evaluation. Yol and colleagues [22] instead found that PRP application increased the bursting strength of intestinal anastomoses in rats. In this case, the difference with our study may be due to differences in species (rat vs pig), intestinal segment (colon vs jejunum) and method of production of PRP.

Certainly, as in the study conducted by Fresno and colleagues, our study is limited from having tested the two treatments together with the control in the same animal. It is possible that this was a confounding factor and that, eventually, resulted in growth factors from one preparation effecting sites that were distant from the application site.

Further studies are needed to prove the effectiveness of platelet rich preparations in species other than rats and in different intestinal segments. Furhtermore, methods that could modulate the final concentration of platelets in the preparation would be beneficial.

\section{Conclusions}

Both PRP and PRGF suspensions should be considered a safe strategy and represent a relatively low-cost technology that are flexible enough to be applied in several therapeutic fields. No true benefit could be proven in our study compared to the no treatment following anastomoses formation, with the exception of enhanced epithelization of the mucosa in the PRGF group. Nevertheless, further studies are required to clarify the molecular mechanisms underlying the biological effects on wound healing and to understand how to improve this promising tool.

\section{Methods}

The study was approved by the Bioethical Committee of the University of Turin and by the Italian Ministry of Health.

\section{Animals}

Eight female pigs (Landrace X Large White), weighing 40 to $48 \mathrm{~kg}$, were kept in standard conditions and fed for 1 week before the experiment. Pigs were randomly assigned to two groups (PRP and PRGF) and subjected to hand sewn jejuuno-jejunal appositional extramucosal anastomoses [22]. For each animal, a total of six anastomoses were performed: two were considered controls and received no treatment, while the remaining four anastomoses were treated with PRP or PRGF, according to the assigned group. In each animal, either PRP or PRGF was used as a treatment, to avoid interference among products. This led to a total of 16 untreated anastomoses (control), 16 anastomoses treated with PRGF, and 16 treated with PRP.

\section{PRP preparation}

For all pigs in the PRP group, blood samples were collected from the jugular vein before surgical procedures, just before induction of anaesthesia. For each pig, $5 \mathrm{~mL}$ blood samples were drawn into 12 different tubes containing buffered $3.8 \%$ sodium citrate. Blood samples were centrifuged at $786 \mathrm{~g}$ for $10 \mathrm{~min}$. Next, supernatant and buffy coat were removed and the remaining sample was centrifugated at $526 \mathrm{~g}$ for $10 \mathrm{~min}$. The resulting pellet consisted of platelets, 
which were harvested and re-suspended with $500 \mu \mathrm{L}$ of supernatant. The suspension was then stored at $20^{\circ} \mathrm{C}$ for a time ranging between 45 and $90 \mathrm{~min}$ before being applied to the anastomotic site. Immediately prior to the application at the anastomotic site, $1 \mathrm{~mL}$ of this suspension was transferred to a Petri dish and $50 \mu \mathrm{L}$ of calcium chloride $(25 \mathrm{mM})$ was added to activate the PRP [3].

\section{PRGF preparation}

Similar to the pigs in the PRP group, blood was collected from all pigs in the PRGF group from the jugular vein just before induction of anaesthesia. For each pig, $5 \mathrm{~mL}$ blood samples were drawn into 12 different tubes containing buffered $3.8 \%$ sodium citrate. Samples were then centrifuged using a PRGF-endoret system ${ }^{1}$ at $580 \mathrm{~g}$ for $8 \mathrm{~min}$. This procedure led to the separation of the different fractions: the first (Fraction 1: F1) containing a platelet count similar to that of peripheral blood, the second (F2) containing a higher quantity of platelets and growth factors, and the third (F3) containing the highest concentration of both platelets and growth factors compared to other fractions. F3 was the only fraction useful for the preparation of PRGF, while F1 and F2 were discarded [4]. Immediately prior to application at the anastomotic site, $1 \mathrm{~mL}$ of suspension, prepared as described above, was transferred to a Petri dish and $50 \mu \mathrm{L}$ of $10 \%$ calcium chloride was added to activate the preparation [5].

For both PRP and PRGF suspensions, both platelet and white blood cell counts were obtained and compared.

\section{Group assignment}

Animals and techniques were assigned randomly, using a random number generator (www.random.org).

\section{Assessment of the characteristics of the autologous preparation}

The number of platelets and leukocytes in swine whole blood (before centrifugation) and in PRGF and PRP fractions was assessed using the Advia 120 Bayer Haematology Analyser ${ }^{1.2}$ Because each autologous preparation (PRP and PRGF) was obtained from animals of two groups, a ratio between the platelet (PLT) count in each preparation and the platelet count of the whole blood (WB) was calculated for each group for comparison purposes using the formula: PLT ratio $=($ PLT count in autologous preparation/PLT in whole blood). Similarly, the ratio between the number of leukocytes in the preparation and the number of leukocytes in the whole blood was obtained using the formula: Leukocyte ratio = Leucocyte count in autologous preparation/Leukocytes in whole blood.

In addition, the collection efficiency (\%) was calculated as follows: (Preparation volume $\times$ preparation PLT count)/ (Whole blood volume $\times$ Whole blood PLT count) $\times 100$ [3] and was compared between groups.

\section{Surgical procedures}

Twelve hours before surgery, animals were not allowed to consume food, but were allowed to consume water ad libitum. Pigs were pre-medicated with an intramuscular injection of xylazine $\mathrm{e}^{23}(2 \mathrm{~mL} / \mathrm{kg}$, intramuscularly [IM]) and anaesthesia was induced using an intramuscular injection of tiletamine and zolazepam ${ }^{34}(4.4 \mathrm{mg} / \mathrm{kg}$, intramuscularly [IM]). The trachea was intubated and anaesthesia was maintained with $2-2.5 \%$ isoflurane ${ }^{45}$ in $100 \%$ oxygen and spontaneous ventilation, with a semi-closed circular anaesthetic system. Animals were placed in dorsal recumbency and the abdomen was shaved and aseptically prepared using $10 \%$ povidone iodine. After a midline laparotomy, the small intestine was exposed. At $30 \mathrm{~cm}$ distally from the Treitz's ligament, six resections were performed on the jejunum, approximately $40 \mathrm{~cm}$ apart.

The methods by which resection and anastomosis formation were performed were standardized to limit the harvesting of tissue such that there would be no differences in vascularization. A wedge of tissue was obtained by cutting the intestine along two lines at an angle of $60^{\circ}$ starting at the same mesenteric site. The anastomotic technique was the same for all anastomoses and was performed by a single surgeon (MG). Resection and anastomosis was performed extracorporeally and moist laparotomic gauzes were used to reduce surgical field contamination

Before anastomosing the two segments, the edges were dipped in the activated PRP or PRGF, according to the allocated group, and maintained for 5 min until the preparation formed a gelatinous clot [3]. The surgeon performing the anastomoses was blinded regarding the treatment. Being careful not to remove this clot, intestinal continuity was then restored with a jejuno-jejunal end-to-end anastomosis, using a single-layer continuous modified appositional extra-mucosal suture [22] with a Glycomer 631 USP 3-0 $0^{5.6}$

As described above, two anastomoses in each subject were used as controls. The intestinal stumps were dipped in $0.9 \%$ sodium chloride solution for $5 \mathrm{~min}$ before application to the anastomosis sites.

No measures were undertaken to reduce the risk of adhesions, other than keeping the intestine moistened during the procedure and, in particular, the anastomotic sites were not covered with omentum. The mesentery was closed with a simple continuous suture with Glycomer 631 USP 3-0.5, 6

The abdomen was closed using a routine, mass simple continuous suture of the fascia with PDS USP $1^{67}$ and with stapled closure of the skin using staples ${ }^{6,7.8}$ Animals were treated preoperatively with a single intramuscular administration of benzipenicillin-diistreptomicine ${ }^{6,7,89}$ (20 $\mathrm{mg} / \mathrm{kg}$, intramuscularly [IM]), while post-operative analgesic therapy consisted of intramuscular buprenorphine $^{7,8,910}(0.01 \mathrm{mg} / \mathrm{kg}$, intramuscularly [IM]) once and 
as needed based upon postoperative monitoring. During recovery, pigs were placed under an infrared heat lamp. After recovery, access to water and food was allowed after 6 and 18 h, respectively.

Postoperatively, pigs were monitored twice daily for fever and pain (which were determined by monitoring the animal's appearance, food intake, activity, and response to wound palpation).

All animals were anaesthetised 8 days after surgery using an intramuscular injection of tiletamine and zolazepam $^{3,4}(4.4 \mathrm{mg} / \mathrm{kg}$, intramuscularly [IM]) and euthanized by intracardiac injection of embutramide, mebenzonium iodide, and tetracaine hydrochloride solution ${ }^{8,9,1011.12}$

\section{Postoperative period}

All animals recovered uneventfully from anaesthesia. Only two pigs showed postoperative pain that was controlled by further doses of buprenorphine.

\section{Macroscopic examination}

Necropsy was performed by an operator blinded to the techniques. During the necropsy, the following findings were recorded: a) adhesions; b) signs of peritonitis; c) anastomotic leakage; and d) presence of abscesses or granulomas at the anastomotic sites. The number of adhesions involving the anastomoses was determined and compared within groups.

The evaluation of adhesions in each anastomotic site was classified according to the scale proposed by Van der Ham et al. [23] and by Wang and colleagues [24] (Table 4).

\section{Bursting pressure}

Directly after euthanasia and necropsy, tThe bursting pressure was measured using a modified inflation tank test $[25,26]$. Intestine portions were closed with plastic tiewraps that were placed $10 \mathrm{~cm}$ proximally and distally to the anastomotic site. At one end, a $20 \mathrm{G}$ needle, attached to a column manometer, was tunnelled through the intestinal wall. Similarly, at the opposite end, another $20 \mathrm{G}$ needle was inserted and attached to a syringe pump. The specimen was maintained in $0.9 \%$ warm saline as the syringe pump ${ }^{11,1213}$ inflated the tissue with air at a rate of $0.5 \mathrm{~L} /$

Table 4 Grading of adhesions

\begin{tabular}{ll}
\hline Score & Description \\
\hline 0 & No adhesion \\
1 & $\begin{array}{l}\text { Minimal adhesions, mainly between the } \\
\text { anastomosis and omentum }\end{array}$ \\
2 & $\begin{array}{l}\text { Moderate adhesion, between omentum } \\
\text { and anastomosis, or between the bowel } \\
\text { and anastomosis } \\
3\end{array}$ \\
& $\begin{array}{l}\text { Severe and extended adhesions with } \\
\text { possible formation of abscesses }\end{array}$ \\
\hline
\end{tabular}

Table 5 Grading of histological parameters

\begin{tabular}{ll}
\hline Score & Description \\
\hline 0 & No evidence \\
1 & Occasional evidence \\
2 & Light scattering \\
3 & Abundant evidence \\
\hline
\end{tabular}

min. The procedure was digitally filmed. Anastomotic leakage and bursting were indicated by the presence of air bubbles and by a sudden pressure stop/drop, as measured by a manometer. The exact peak pressure was reported with the help of videography [25]. The bursting pressures of healthy intestinal samples distant from the anastomotic sites during necroscopy were also recorded as controls [27].

All samples were sectioned longitudinally on the antimesenteric margin and fixed in 10\% buffered formalin.

\section{Histology}

Bowel samples were fixed in $10 \%$ buffered formalin, embedded in paraffin, cut into 4- $\mu \mathrm{m}$ sections, stained with haematoxylin and eosin $(\mathrm{H} \& \mathrm{E})$, and examined by two blinded expert pathologists to evaluate inflammation and neovascularisation. Sample slices were also stained with Masson's trichrome to assess fibroblast proliferation. Each parameter (i.e., epithelialization/ulceration, inflammatory infiltrate, proliferation of fibroblasts, neovascularization, and deposition of collagen) was scored on a scale proposed by Erlich et al. and modified by Philips et al. [28, 29] (Table 5).

\section{Statistical analysis}

Data are presented as median (range). Normality of data was determined by the Shapiro-Wilk test. To compare platelet and leukocyte counts, an unpaired Student's $t$-test with Welch's correction was used, while the Mann-Whitney test was employed to compare ratios. The KruskalWallis test with Dunn's multiple comparison tests was used to compare bursting pressures and histological parameters.

The number of adhesions per group was compared using the Chi square test, while the mean adhesion score for each group was compared using the Kruskal-Wallis test with Dunn's post-hoc test. Data were analysed using GraphPad Prism 6.0 software $^{9}$ software ${ }^{12,13}$ and a $P$-value $<0.05$ was considered significant.

\section{Endnotes}

${ }^{1}$ BTI Biotechnology Institut, Milano, Italy

${ }^{2}$ Siemens AG, Wittelsbacherplatz, Munich, Germany

${ }^{3}$ Bayer Animal Health, Monheim, Nordrhein-Westfalen, Germany

${ }^{4}$ Virbac Italia, Milano, Italy

${ }^{5}$ Esteve Italia spa, Milano, Italy

${ }^{6}$ Covidien, Segrate Milano, Italy

${ }^{7}$ Johnson and Johnson, Milano, Italy 
${ }^{8}$ Weck Visistat R35

${ }^{9}$ Fatro, Ozzano dell'Emilia, Italy

${ }^{10}$ Schering-Plough, Segrate Milano, Italy

${ }^{11}$ Intervet Italia srl, Segrate Milano, Italy

${ }^{12}$ Care Fusion, Firenze, Italy

${ }^{13}$ GraphPad Software Inc., La Jolla, USA

\section{Additional file}

Additional file 1: Cerficate of English Editing. (PDF 238 kb)

\section{Abbreviations}

IM: Intramuscularly; PDGF: Platelet-derived growth factors; PLT: Platelet; PRGF: Preparations rich in growth factors; PRP: Platelet-rich plasma; TGF$\beta$ : Transforming growth factor- $\beta$; VEGF: Vascular endothelial growth factor; WB: Whole blood

\section{Acknowledgements}

None

\section{Funding}

This study was funded by the Veterinary Teaching Hospital, Fondo Rinuncia Prestazioni, to MG

\section{Availability of data and materials}

The datasets supporting the conclusions of this article are included as Additional file 1. They can be shared upon request.

\section{Authors' contributions}

MG and GG developed the study, performed the surgeries, as well as wrote and revised the manuscript. CV wrote and revised the manuscript. SI and MT performed the pathologic examination, and revised the manuscript. GP performed the anesthesia, performed the bursting pressure testing and revised the manuscript. All authors read and approved the final manuscript.

\section{Competing interests}

The authors declare that they have no competing interests.

\section{Consent for publication}

Not applicable

\section{Ethics approval and consent to participate}

The study was authorized by the Bioethical Committee of the University of Turin and by the Italina Ministry of Health. Authors adhered to the ARRIVE guidelines

\section{Disclosures}

Authors have no conflicts of interest or financial ties to disclose

\section{Publisher's Note}

Springer Nature remains neutral with regard to jurisdictional claims in published maps and institutional affiliations.

Received: 30 November 2015 Accepted: 9 June 2017

Published online: 19 June 2017

References

1. Hyman N, Manchester TL, Osler T, Burns B, Cataldo PA. Anastomotic leaks after intestinal anastomosis: it's later than you think. Ann Surg. 2007;245:254-8.

2. Øines MN, Krarup PM, Jorgensen LN, Agren MS. Pharmacological interventions for improved colonic anastomotic healing: a meta-analysis. World J Gastroenterol. 2014:20(35):12637-48

3. Fresno L, Fordevila D, Bambo O, Chacaktana A, Garcià F, Andaluz A. Effects of platelet-rich plasma on intestinal wound healing in pigs. Vet J. 2010;185(3):322-7.

4. Anitua E, Muruzabal F, De la Fuente M, Merayo-Lloves J, Orive G. Effects of heat-treatment on plasma rich in growth factors-derived autologous eye drop. Exp Eye Res. 2014;119:27-34.
5. Anitua E, Prado R, Sànchez M, Orive G. Platelet-rich plasma: preparation and formulation. Oper Tech Orthop. 2012;22:25-32.

6. Anitua E, Sanchez M, Orive G. The importance of understanding what is platelet-rich growth factor (PRGF) and what is not. J Shoulder Elb Surg. 2011;20(1):e23-4.

7. Dohan Ehrenfest DM, Rasmusson L, Albrektsson T. Classification of platelet concentrates: from pure platelet-rich plasma (P-PRP) to leucocyte- and platelet-rich fibrin (L-PRF). Trends Biotechnol. 2009:27:158-67.

8. Anitua E, Alkhraisat MH, Orive G. Perspective and challenges in regenerative medicine using plasma rich in growth factors. J Control Release. 2012;157(1):29-38.

9. Alsousou J, Thompson M, Hulley P, Noble A, Willett K. The biology of platelet-rich plasma and its application in trauma and orthopaedic surgery. $J$ Bone Joint Surg. 2009:91B:987-96.

10. Cocero N, Pucci F, Messina M, Pollio B, Mozzati M, Bergamasco L. Autologous plasma rich in growth factors in the prevention of severe bleeding after teeth extractions in patients with bleeding disorders: a controlled comparison with fibrin glue. Blood Transfus. 2014;29:1-8.

11. Lange-Consiglio A, Spelta C, Garlappi R, Luini M, Cremonesi F. Intrammamary administration of platelet concentrate as an unconventional therapy in bovine mastitis: first clinical application. J Diary Sci. 2014;97:6223-30.

12. Lange-Consiglio A, Cazzaniga N, Garlappi R, Spelta C, Perrini C, Cremonesi F. Platelet concentrate in bovine reproduction: effects on in vitro embryo production and after intrauterine administration in repeat breeder cows. Reprod Bio Endocrinol. 2015;13:65.

13. Anitua E, Zalduendo MM, Alkhraisat MH, Orive G. Release kinetics of platelet-derived and plasma-derived growth factors from autologous plasma rich in growth factors. Ann Anat. 2013;195:461-6.

14. Thornton FJ, Barbul A. Healing in the gastrointestinal tract. Surg Clin North Am. 1997;77(3):549-73

15. Yamaguchi R, Terashima H, Yoneyama S, Tadano S, Ohkohchi N. Effects of platelet-rich plasma on intestinal anastomotic healing in rats: PRP concentration is a key factor. J Surg Res. 2012;173:258-66.

16. Hedlund CS. Surgery of the small intestine. Surgery of the digestive system. In: Small animal surgery. Second ed. St Louis: Mosby Inc.; 2002. p. 369-98.

17. Brochhausen C, Schmitt VH, Rajab TK, Planck CNE, Kramer B, Wallwiener M Hierlemann H, Kirkpatrick CJ. Intraperitoneal adhesions-an ongoing challenge between biomedical engineering and the life sciences. J Biomed Mat Res Part A. 2011;98A:143-56.

18. Biellecki T, Cieslik-Bielecka A, Aelawski M, Mikusek W. A side-effect induced by the combination of a demineralized freeze-dried bone allograph and leucocytes and platelet-rich plasma during treatment for large bone cysts: a 4-year follow-up clinical study. Transfus Apher Sci. 2012;47:133-8.

19. Filardo G, Kon E, Preira RM, Vaccaro F, Guitaldi R, Di Martino A, Cenacchi A, 471 Fornasari PM, Marcacci M. Platelet-rich plasma intraarticular injections for cartilage de generation and osteoarthritis: singleversus soluble-spinning approach. Knee Surg Sports Traumatol Arthrosc. 2012:20:2082-91.

20. Del Buono A, Osti L, Maffulli N. Platelet-rich plasma: anatomical application to date: does it really work? Oper Tech Orthop. 2013;23:75-7.

21. Graziani F, Ivanovski S, Cei F, Tonetti M, Gabriele M. The in vitro effect of different PRP concentrations on osteoblasts and fibroblasts. Clin Oral Implants Res. 2006;17(2):212-9.

22. Yol S, Tekin A, Yilmaz H, Küçükkartallar T, Esen H, Caglayan O, Tatkan Y. Effects of platelet rich plasma on colonic anastomosis. Surg Res. 2008;146:190-4.

23. Gandini M, Giusto G, lussich S, Tursi M, Perona G. A continuous single-layer extramucosal appositional suture pattern for end-to-end jejunojejunostomy in horses. In vitro study. Budapest: Proceeding of the 49th Congress of the European Society for Surgical Research (ESSR); 2014.

24. Van der Ham AC, Kort WJ, Weijma IM, van den Ingh HF, Jeekel J. Effect of fibrin sealant on the healing colonic anastomosis in the rat. $\mathrm{Br} J$ Surg. 1991;78:49-53.

25. Wang P, Wang J, Zhang W, Li Y, Li J. Effect of the combination of fibrin glue and growth hormone on intestinal anastomoses in a pig model of traumatic shock associated with peritonitis. World J Surg. 2009;33:567-76.

26. Gandini M. Handsewn semiclosed single-layer jejunocecal side-to-side anastomosis in the horses. Vet Surg. 2010;39(6):771-5. 
27. Zhou B, Ren J, Ding C, Wu Y, Hu D, Gu G, et al. Rapidly In Situ forming plateletrich plasma gel enhances Angiogenic responses and augments early wound healing after open abdomen. Gastroenterol Res Pract. 2013;926764

28. Ikeuchi D, Onodera H, Aung T, Kan S, Kawamoto K, Imamura M, Maetani S. Correlation of tensile strength with bursting pressure in the evaluation of intestinal anastomosis. Dig Surg. 1999;16:478-85.

29. Ehrlich HP, Tarver H, Hunt TK. Effects of vitamin a and glucocroticoids upon inflammation and collagen synthesis. Ann Surg. 1973;177(2):222-7.

Submit your next manuscript to BioMed Central and we will help you at every step:

- We accept pre-submission inquiries

- Our selector tool helps you to find the most relevant journal

- We provide round the clock customer support

- Convenient online submission

- Thorough peer review

- Inclusion in PubMed and all major indexing services

- Maximum visibility for your research

Submit your manuscript at www.biomedcentral.com/submit 